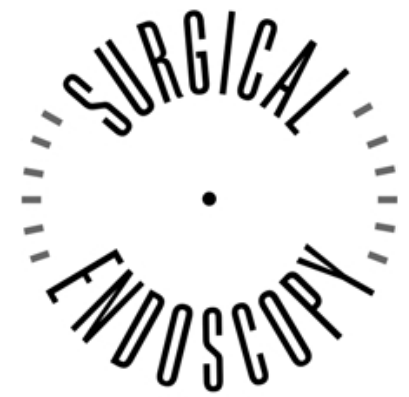

and Other Interventional Techniques

\title{
Alvimopan, a perpherally acting mu-opioid receptor antagonist, compared with placebo in postoperative ileus after major abdominal surgery
}

\author{
Results of a randomized, double-blind, controlled study \\ E. R. Viscusi, ${ }^{1}$ S. Goldstein, ${ }^{1}$ T. Witkowski, ${ }^{1}$ A. Andonakakis, ${ }^{1}$ R. Jan, ${ }^{1}$ K. Gabriel, ${ }^{1}$ W. Du, ${ }^{2}$ L. Techner, ${ }^{2}$ B. Wallin ${ }^{2}$ \\ ${ }^{1}$ Jefferson Medical College, Thomas Jefferson University, 111 South 11th Street, Suite G8490, Philadelphia, PA 19107-5092, USA \\ 2 Adolor Corporation, Exton, PA, USA
}

[Surg Endosc (2006) 20: 64-70, DOI: 10.1007/s00464-005-0104-y]

On page 65, in column 1 of the "Patients and methods" section, the wrong study number was published. The first sentence under the heading "Study design and treatments" should read:

This was a randomized, double-blind, placebo-controlled, parallel-group, phase III trial (Study 14CL308) designed to evaluate the efficacy and safety of 6 and 12 $\mathrm{mg}$ alvimopan for the management of POI in patients undergoing BR or TAH. 